\title{
Community Participation and Challenges in controlling Female Genital Mutilation in A Rural Community of Southwest Ethiopia: A Mixed Study
}

Melsew Setegn ( $\sim$ melsewsetegn2010@gmail.com )

Mizan Tepi University

\section{Research Article}

Keywords: Female gentile mutilation, community participation, Southwest Ethiopia

Posted Date: February 1st, 2021

DOl: https://doi.org/10.21203/rs.3.rs-149718/v1

License: (c) (1) This work is licensed under a Creative Commons Attribution 4.0 International License.

Read Full License 


\section{Abstract \\ Background}

Female gentile mutilation is all procedures that involving the partial or total removal of external genitalia or other injury to female genital organs. More than 140 million women in the world have undergone female gentile mutilation. In many rural parts of Africa, local communities' low involvement and existence of diverse challenges during community participation supported to the persistence of female gentile mutilation practices. Community participation can empower and provide local people with opportunity to think and develop solutions for themselves by incorporating local knowledge and skills in the process of taking part. Increasing community participation has power in controlling such challengeable social issue in creating common consensus and sense of responsibility among local community. Therefore, this study was aimed to assess the role of community participation and challenges in controlling the female genital mutilation in rural community of southwest Ethiopia.

\section{Methods}

A community based cross sectional study was conducted from November 1-30, 2020 in southwest Ethiopia among 403 study participants. A multi-stage stratified sampling technique was used and the study participants was selected systematically after proportional allocation to size was done. The data were collected in both qualitative and quantitate approach so focused group discussion, key informant interview and face-to-face interview was used to collect data respectively.

\section{Results}

The response rate of the study was $91.3 \%$ of them completed the interview. From this as the total response rate indicated that $65.8 \%$ females and $34.2 \%$ male responded. The result indicated that among participant females $79.27 \%$ circumcised. From the participant, $70.1 \%$ of respondents not support community participating in control of female genital mutilation. The result of this study indicates that majority, $92.2 \%$ of the respondents believe $(M=4.48, S D=0.639)$ that community participation can help the actors to left female genital mutilation practice in the community. The influence of community participation in making decision to left circumcision of once daughter in the future. The result revealed that $45.0 \%$ and $44.4 \%$ of respondents perceive $(M=4.34, S D=0.661)$ community participation influence the future actions of an individual can be high and very high respectively. The challenges identified in the current study were changing tradition of female circumcision from public to secrecy, lack of decision making among local people, lack of open discussion among rural community, submissive participation by women in FGM controlling process, intervention of local administration and preference of donors' problems. 


\section{Conclusion and recommendations:}

The practice of FGM in the study are high since the goal of sustainable development goal is zero. Lowe attitude and perception towards female genital mutilation is study area. Majority of FGM practice was done health professionals in secret way. This implies that more intervention is needed for the reduction of its practice. The government should work with the community and should consider culturally appropriate and socially acceptable policies and strategy to reduce the practice.

\section{Introduction}

Female gentile mutilation (FGM) is all procedures that involving the partial or total removal of external genitalia or other injury to female genital organs for non-beneficial reasons[1]. Globally, at each year three millions of girls and women subjected to genital mutilation that causes unspeakable pain and suffering $[2,3]$ study indicated more than 135 million women and girls worldwide are currently living with the upshot of FGM. The one-study estimation more than 140 million women in the world have undergone FGM. The majority of these risk-taking females are living along in Africa[4].

In many rural parts of Africa, local communities' low involvement and existence of diverse challenges during CP supported to the persistence of FGM practices[5]. Rigorously, in Africa the estimation indicated that 92 million girls and women have already undergone FGC and nearly 3 million girls are at risk of female genital cutting (FGC) annually[3].

Among others, the practice result stern problems in Ethiopia, Egypt, Djibouti, Guinea, Mali, Somalia and Sudan between $85 \%$ and $99 \%$ of the female population is circumcised[6]. Particular, the most severe and worst form of the procedure practiced in Ethiopia, Djibouti, Eritrea, Somalia, and Sudan[7]. The Norwegian Child Aid and Save the Children, indicated that more than 200 million women and girls worldwide have undergone FGM; Ethiopia shared 23.8 million[8]. In average, Ethiopia encloses moderately high FGM prevalence between $51 \%$ and $80 \%$ [9]. Between 2005 and 2016, the overall prevalence for women aged 15-49 in Ethiopia fell from 74.3-65.2\%. Specifically, according to Demographic Health Survey of Ethiopia carried out in countryside with national prevalence rate of $65.2 \%$. In Ethiopia, the issue is one of serious problem along with this rural community[10].

Women and girls are undertaking routinely experience of pain, physical and emotional trauma, and health complications because of infection during or after circumcision. Moreover, many of circumcised girls commonly shared problems such as acute anxieties, depression, stress and disorder that interfere with their social lives[11].

Community participation can empower and provide local people with opportunity to think and develop solutions for themselves by incorporating local knowledge and skills in the process of taking part. Increasing $\mathrm{CP}$ has power in controlling such challengeable social issue in creating common consensus and sense of responsibility among local community. As well the $\mathrm{CP}$ and their engagement can benefit 
local people in terms of empowerment, effectiveness, openness, enhancing their capabilities and promoting self-assurance in decision-making process to undertake this common problem[12].

Specifically, in rural area the numerous women and girls suffer in genital mutilation and them unable to survival. There are inert many challenges though to overcome this risk of FGM problem. One of extended challenges is due to lack of clear involvement in effectively and unsuccessful intervention designed to eliminate FGM risk among local communities. Patently, absence of extensive community participation and lack of a very strong legal as well as community education response that make challenges in controlling process $[13,14]$. The inactive local communities' involvement and its stumpy participation by rural people in controlling FGM risk lead to feeble decision-making, which support to suspended the lives of thousands and millions of women[15]. communities objective was to guarantee females purity and virginity which taken as precondition for an honorable marriage and basis of economic survival for women[16, 17].

Ethiopia has undertaken significant 'gender-sensitive' legislative reforms laws are the 1995 FDRE constitution, the 2003 Revised Family Law and the 2004 Criminal Code. The main law governing FGM in Ethiopia is Proclamation No. 414/2004, the Revised Criminal Code of the Federal Democratic Republic of Ethiopia 2005 and Articles 561-570 are relevant to FGM, but law enforcement is weak and few cases reach court[18]. To solve the issue at national stage, Ethiopian government on Girl's Summit in London also forwards the groundbreaking commitment to end FGM by 2025[19]. Despite of national commitment, in the study area the rural community continued commonly to practice FGM and there no current evidence about community involvement on it. Therefore, this study was aimed to assess the role of community participation and challenges in controlling the Female Genital Mutilation in rural community of southwest Ethiopia.

\section{Methods}

\section{Study area and period}

A community based cross sectional study was conducted from November 1-30, 2020 in southern nation nationality of Ethiopia in rural community. According to the population projection of Nov 2010, the total population of the Woreda is 121,241 , which are composed of 60,660 females and 60,581 males. It has twenty-one Kebele from which Seventeen are rural, four are urban administrative centers, and it is 77 kilometers of all-weather roads and 45 kilometers of dry-weather roads, for an average road density of 381 kilometers per 1000 square kilometers.

\section{Source population}

All households in the selected woreda 


\section{Study population}

The participants were both men and women at household level. Those participants were the individuals who meet the selection criteria and them drawn from selected rural Kebeles. All head or spouse of households who were seriously ill or unable to communicate during data collection excluded from the study. In addition, the category of both women and men who have no daughter at household level and below age 18 not selected.

\section{Sampling technique and procedure}

The sample size was determined by using single population proportion formula with the assumption of $95 \%$ confidence level, $5 \%$ margin of error and the proportion of FGM community participant $50 \%$.

$n=(z a / 2)^{2 *} p^{*}(1-p) / d^{2}$

Where; $\mathrm{n}=$ sample size

$\mathrm{Za} / 2=95 \%$ confidence interval $(1.96)$

$\mathrm{P}=50 \%$ since there is no previous study

$d=5 \%$ margin of error

Based on the above assumption

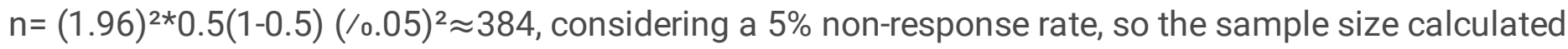
from single population proportion was 403 .

Multi-stage stratified sampling technique that involves subdivision of the population sampled into mutual exclusive groups. One woreda were selected purposively then in the first stage the woreda were stratified into town administrator and rural woreda administrator. In the second stage woreda administrator were stratified into rural and urban then the study participants were selected by systematic random sampling techniques. The study participants were selected every three household in the study area. When there were no eligible study participants in the selected house, nearby house was selected and interviewed. In case of more than one eligible woman were encountered in the selected household, a lottery method was used to determine which household would be interviewed.

\section{Data collection personnel}

The quantitative data were collected by five BSc degree holder nurses and supervised by two health officers. The qualitative data were collected by three MPH in health education specialty experts with quite procedures. 


\section{Data collection process}

Pretested interviewer-administered structured questionnaire was adapted from different literatures. The questionnaire was prepared first in English and then translated to local language (Amharic) and was retranslated back to English by another person to ensure its consistency and accuracy. Experts were assessed whether the data collection tool measures what it intended to measure and it was comprehensive enough to collect all the information needed to address the objective of the study. Cronbach's a coefficient were computed to test the internal consistency of the tool and it was indicates the tool is reached at acceptable level of reliability.

A qualitative method has used open-ended questioners' to get qualitative information from FGD and key informant interviews.

\section{Focused Group Discussions}

There were three FGD groups with each group contained 10 participants during discussion. Totally, the researcher used 30 participants in three groups for FGD. The first group was from experienced women, second group from both circumcised or uncircumcised women and girls, and third group FGD participants were from religious individuals (protestant, orthodox, Catholic and Muslim) study population. The researcher wrote the letter to targeted FGD participants, above age 18. During the discussion, participants made free expression of their thoughts, emotions and ideas through their own consent and willingness by focusing experience of FGM practice in their local community. Employing FGD is keys to know communities awareness, their perceptions, attitudes and experiences that are not reveal at individual participant.

\section{Key informant interviews}

The researcher employed the person-to-person interview and used the tape record and take notes during interview. As a data collection tool, interviews were conducted with 8 key informants purposively include from women, children and youth affairs office (2), Woreda Council (1), health professional (1), community leaders (1), KMG coordinators (1), community polity (1) and practitioners of FGM (1). Interviews allowed researcher to collect general information on the trends and contexts in which FGM practiced in the community.

\section{Data management and analysis}

Auditing, coding and sorting of the collected questionnaire was done manually every day to check for completeness. After checking the completeness of the data, the data were entered by Epi-data manager version 3.1 and then exported to SPSS version 24 statistical package for analysis. Descriptive analysis 
was done for dependent, other variables, and presented in terms of frequency, mean, percentage, and text. The qualitative data were analyzed by Atlas ti 7 by creating codes, categories and themes after reading and rereading of the data collected by experts. Finally, it is presented with the quantitative data by triangulations.

\section{Data quality control}

The questionnaire was first prepared in English and then translated to Amharic and re-translated back to English by other person to ensure its consistency and accuracy. Pre-test was carried out in other woreda on $5 \%$ of the sample size before actual data collection period. After conducting pre-test, some correction of tool was done. Internal consistency reliability analysis was carried out and Cronbach's alpha showed the questionnaire reached acceptable reliability. Training was given for one day for both data collectors and supervisors. The supervisors supervise the performance of the data collectors on daily basis. The collected data were checked for completeness, consistency and clarity by principal investigator and trained supervisors.

\section{Results}

\section{Socio-economic and demographic characteristics}

The response rate of the study was $374(91.3 \%)$ of them completed the interview. From this as the total response rate indicated that $246(65.8 \%)$ females and $128(34.2 \%)$ male responded. Participants asked to respond at which age category they belong. The findings revealed $170(45.4 \%)$ of respondents at age category of $24-30$ years. Regarding the religious of respondents, majority $337(90.1 \%)$ were protestant religion follower. Concerning the educational level of respondents, 120 (32.08\%), participants attended secondary education. The finding showed that majority of respondents were married, 321 (85.8\%). Regarding the occupational status of respondents, majority 322 (86.09\%) participants were engaging their economic activities by farming or they were farmers. Regarding the economic status of the study participants were the majority, 234(62.5\%) were their income level between 1000 and 1500 birrs (Table 1). 
Table 1

Socio-economic and demographic characteristics of the study conducted in southwest Ethiopia $(n=374)$

\begin{tabular}{|c|c|c|c|}
\hline Variables & Category & Frequency & Percent \\
\hline \multirow[t]{4}{*}{ Age of respondents } & $15-24$ years & 49 & 13.1 \\
\hline & $25-30$ years & 170 & 45.4 \\
\hline & $31-49$ years & 110 & 29.4 \\
\hline & $>=50$ years & 45 & 12.1 \\
\hline \multirow[t]{2}{*}{ Religion } & Protestant & 337 & 90.1 \\
\hline & Otherst & 37 & 9.9 \\
\hline \multirow[t]{2}{*}{ Sex } & Male & 128 & 34.2 \\
\hline & Female & 246 & 65.8 \\
\hline \multirow[t]{2}{*}{ Marital status } & In marital union & 321 & 85.8 \\
\hline & Not in marital union & 53 & 14.2 \\
\hline \multirow[t]{4}{*}{ Educational status } & No formal education & 90 & 24.1 \\
\hline & Primary $(1-8)$ education & 112 & 29.9 \\
\hline & Secondary $(9-12)$ & 120 & 32.1 \\
\hline & Tertiary $(>12)$ & 52 & 13.9 \\
\hline \multirow[t]{2}{*}{ Main occupation of respondent } & Employed & 52 & 13.9 \\
\hline & Farmer & 322 & 86.1 \\
\hline \multirow[t]{2}{*}{ Total family size } & $\leq 4$ & 271 & 72.5 \\
\hline & $>4$ & 103 & 27.5 \\
\hline \multirow[t]{4}{*}{ Income level } & $<=500$ birr & 80 & 21.4 \\
\hline & 500-1000birr & 234 & 62.5 \\
\hline & 1001-1500birr & 50 & 13.4 \\
\hline & $>=15001 \mathrm{birr}$ & 10 & 2.7 \\
\hline
\end{tabular}

\section{Current condition of rural peoples involvement in controlling FGM}

The result indicated that among participant females, 195(79.27\%) circumcised. The findings addressed that among participant women majority of them circumcised. This finding also supported by qualitative finding which revealed that still majority of rural communities continued performing FGM. A 32 years old 
FGD participant woman stated as: "Circumcision of females might be required as un-circumcision till results fear and marginalization inside community. Inside local community, un-cutting women and girls faced less social acceptance, burden to family, and lack marriage. Besides, she added marriage without un-circumcision lead stumpy acceptance by her husband, during conflict insulting by her neighbors, and lack of confidence was rooted problems. Therefore, the circumcision is the more necessary to females unless communities jointly participate to control FGM in commonalty".

One of the key informant interviewee stated as: "She has daughter and she will not happy to circumcise her daughter but the social factors pushed her to entail FGM practice."

The respondents asked to know whether at present who make decision to perform FGM practice. The result indicated that mother had largest portion of 230 (61.5\%) regarding decision making to perform FGM. The study found that relatively both father and mother are largely shared decision making. In addition, the finding revealed that majorly mother was the main decision-maker to practice FGM.

The findings revealed that based on participants' response frequency distribution and percentage the father had slightly better consciousness than mothers in controlling FGM practice. Mothers were encouraged FGM practice more than fathers does. Also the qualitative data showed that one of 35 years old FGD participant woman, both father and mother were decision makers whether their daughters should be circumcised or not. In addition, she addressed that both father and mother had advanced position and equitable role correspondingly, what legal instrument had play to control FGM. Moreover, having low decision making responsibility by father and mother in particular and low families participation in general become reasons to continuation and develop into obstacles to control FGM.

One of 37 years old, interviewee man expressed as:

...the existence of contradiction among local peoples regarding FGM practice. On one hand, legal instrument strongly recommended community members as not practice FGM by recognizing physical complication. Whereas on the other hand, family members and the rest community as whole continued to perform FGM secretly mainly to kept marriageability to their daughters. He added that disheartened cooperation and inconsiderate participation of families, groups, and communities entirely confronted controlling activity of FGM.

From the total respondents majority, 277 (74.0\%) of them were currently FGM practice performed by health professionals. This indicated that health professionals were deeply involved in female circumcision. This supported by FGD participant woman, 41 years old, discussed that there was diminutive $\mathrm{CP}$ in addressing secret FGM practitioners that facilitated and created excellent opportunity to Actors. In addition, she addressed that practitioners' full confidence in performing FGM in their own home and females went to private health centers to circumcision purpose at evening time.

According to Woreda administrative office key informant, 43 years old expression: 
...he addressed that FGM still performing in a rural community and perform by both traditional and health professionals in secretly. Whatever the practice said to be performed clandestinely all sections of community familiar with when and how practitioners accomplish FGM. It is so much difficulty to take administrative measures since his fear those social sanctions to his family and to himself. If he attempted to do this correspondingly individual family member, clans and community together might revenge against him.

One of ex-circumciser man expressed that, "...he had well experienced with male circumcision for long. He added male circumcision was very tiresome, time consuming, low income or cheap price, energy loose and it need additional ingredient to make wound heal; whereas regarding FGM practice, he experienced so late as compared with male circumcision. Furthermore, he explained his familiarity with types of cutting during FGM practice. Sometimes circumcised girls advised to decide what type of cutting them more preferred."

Respondents asked whether practicing FGM continued in their community or not, most 252(67.4\%) respondents favored practicing FGM continued in their community. The findings revealed that majority of respondents preferential to practicing FGM continued in their community (Table 2). The 31 years old FGD participant woman discussed as: she believed that entire community widely continued practicing FGM in progressively. But she alerted with this problem and she discussed to avoid by participation of community members in collaborative and organized circumstance by reinforcing local people involvement in controlling activity".

".....She also added the participation of educated classes including physicians and other health professionals have power to ban FGM rather than engaging in performing FGM practice. The rural communities silence for a long in controlling FGM come to end with organized participation of government partners, collaborative work between court and police office, and religious community participation. Therefore, the community participation and mobilization act of all groups of societies contributed in controlling secret activities of practitioners among rural community". 
Table 2

Current condition of rural people's participation in controlling FGM in current study, 2020

\begin{tabular}{|c|c|c|c|}
\hline Variables & Category & Frequency & Percen \\
\hline \multirow[t]{2}{*}{ Are you circumcised? } & Yes & 195 & 79.3 \\
\hline & No & 51 & 20.7 \\
\hline \multirow[t]{2}{*}{ Decision for circumcision } & Father & 144 & 38.5 \\
\hline & Mother & 230 & 61.5 \\
\hline \multirow[t]{2}{*}{ Circumcisers who currently perform FGM practice } & Traditional practitioner & 97 & 26.0 \\
\hline & Health professionals & 277 & 74.0 \\
\hline \multirow[t]{2}{*}{ FGM still continued in your local community } & Yes & 252 & 67.4 \\
\hline & No & 122 & 32.6 \\
\hline \multirow[t]{2}{*}{ Cultural acceptability for FGM } & Yes & 309 & 82.6 \\
\hline & No & 65 & 17.4 \\
\hline \multirow[t]{2}{*}{ Community support } & Yes & 286 & 76.5 \\
\hline & No & 88 & 23.5 \\
\hline \multirow[t]{2}{*}{ Active involvement community on control of FGM } & Yes & 94 & 25.1 \\
\hline & No & 280 & 74.9 \\
\hline
\end{tabular}

The findings revealed that 169 (45.2\%) respondents favored as they had learned about the CP to control FGM. This result revealed that majority of participants had not learned on the role of local CP in controlling FGM. Thus, the findings indicated that there is absence of masses of people participation in controlling FGM that lead to persistence and continuation of the practice inside local community for long period.

Respondents had asked whether village community participating to control FGM. Where $262(70.1 \%)$ respondents not support as village community participating in control of FGM. The result showed that majority of respondents was not support as village community not participating at FGM controlling activity. Thus, the findings revealed that if village community participating in control of FGM it has ranges of activities and efforts in considering negative impact of FGM during controlling process.

Respondents also asked whether local government involving in control of FGM practice in their local area. The majority, 300 (80.2\%) respondents were not believed local government involvement in FGM controlling activity. The result indicated that majority of respondents believed non-involvement of local 
government in FGM controlling activity in their local area. This revealed that the low participation of local government and its weak influence in FGM controlling process.

Regarding persistence of FGM, participants had asked whether community participation enabling to control continuation of FGM practice in rural area. Majority, 273 (73.0\%) respondents were supported the CP facilitated the controlling activities of FGM. Participants asked about CP bring practical change in controlling FGM practice in their local area. Majority, 275(73.5\%) respondents supported as local community had bring practical change in controlling FGM practice.

The majority of participants, 258(69.6) percent responded that absence of all local community groups actively participation in rural area is slightly low and there was less controlling mechanisms. Consequently, the low CP and their weak involvement majorly prolonged the controlling activity of FGM practice (Table 3).

Table 3

Community awareness on rural people's participation in controlling FGM in current study, 2020

\begin{tabular}{|llll|}
\hline Variables & Categories & frequency & percent \\
\hline $\begin{array}{l}\text { Have you learned about community participation to control } \\
\text { FGM practice? }\end{array}$ & Yes & 169 & 45.2 \\
\hline Do you think village people participating to control FGM? & No & 205 & 54.8 \\
\hline $\begin{array}{l}\text { Do you agree local government involving in controlling FGM } \\
\text { practice in your local area }\end{array}$ & No & 112 & 29.9 \\
\hline $\begin{array}{l}\text { Is community participation enabling to control continuation of } \\
\text { FGM practice in rural area? }\end{array}$ & Yes & 106 & 70.1 \\
\hline $\begin{array}{l}\text { Does community participation have play functionality role in } \\
\text { controlling FGM? }\end{array}$ & No & 262 & 71.2 \\
\hline $\begin{array}{l}\text { Do you believe communities recognize negative social } \\
\text { implication of FGM practice? }\end{array}$ & No & 101 & 73.0 \\
\hline $\begin{array}{l}\text { Are entire community groups actively participating to control } \\
\text { FGM practice in your rural area? }\end{array}$ & Yes & 137 & 27.0 \\
\hline
\end{tabular}

\section{Attitude towards the role of Community Participation in controlling FGM practice}

The result of this study indicates that majority, 345(92.2\%) of the respondents believe $(M=4.48, S D=$ 0.639 ) that community participation can help the actors to left FGM practice in the community. This 
indicates that, if community participates in awareness creation of the negative consequences of FGM, the members of that community can reduce the practice and in the long run they may stop the practice.

Regarding the community member's engagement in the practice of FGM, the study revealed that majority, $(82.9 \%)$ of respondents agree and strongly agree with the statement "FGM practice is not often performed by traditional practitioners in my local areas". The mean value $(M=4.24, S D=0.726)$ also shows the lowlevel of traditional practitioners engagement in FGM activity. On the other, the study revealed that majority of FGM performed by Health Professionals. Accordingly, the result indicated that almost all (94.1\%) respondents agree and strongly agree with the statement "currently the circumcisers are the educated health professionals that perform the activity in secret manner". The mean value ( $M=4.62, S D=.0556)$ shows high level of respondents agreement with the statement.

Key informants elaborated that the health professional performed FGM in their own house and sometimes at their private health centers. From the above result it is reasonable to conclude that even though FGM considered as a health problem and prohibited by the health professional publicly, still the real attitude of educated people also guided by the locals' perception.

Moreover in this study, the capabilities of community participation in breaking continuation of FGM practice assessed. In this regard the result of this study revealed that community participation has the capacity to break continuation of FGM practices. Accordingly, majority of (88\%) respondent agree and strongly agree with the statement "community participation is capable to break persistence of FGM practice by assessing the challenging factors that burdens the decision -making capacity of women and children". The mean $(M=4.41, S D=0.669)$ value also show that respondents perception towards the statement is positive.

In complementing the survey data from key informant interview. In this regard, a 39 years old key informant stats his perception in the following way:

"...the persistence of FGM attributed to fear of social pressure and it influenced by traditional beliefs within community. These include the uncircumcised women were less immoral as compared to circumcised women".

Moreover, a 33 years old female key informant from Woreda health office said that

“....FGM has continued because people in the community believed that nobody leaves outside the social norms and culture of that society. One of the FGDs participant thought, "Yes, I am aware to avert circumcision of girls and women but I hadn't know the women and girls who were not circumcised in my village among the married women". She forwarded the reason behind absence of more uncircumcised women and girls in her neighborhood. Un-circumcision results the social sanctions towards girls and their family accordance with the social norms of this local community. "For instance, during social conflict people preceding uncircumcised women and girls by way of they are unable to talk because their clitoris 
is not cut and their tongue like that of clitoris so that uncircumcised women and girls lacked selfconfidence and social become dishonor in the community".

The above survey and qualitative data indicated that if community participate in the process of controlling FGM, they have the capacity to alleviate the practices of FGM in their surroundings. Hence, the cultural values of a society maintained by community members. As a result, they have the capacity to deal with the belief system of the community.

Besides, this study assessed whether the participation of religious institutions have a contribution in controlling FGM practices or not. In this regard, the result of this study found out that participation of religious institutions has a contribution in controlling FGM practices. Accordingly, the result show most of respondents agree and strongly agree with the statement "Participation of Religious institutions can contribute a lot in controlling FGM practices" and they perceive $(M=4.18, S D=0.505)$ that there is a positive relation with FGM and religious institutions participation in the study area.

Among the study participants, the majority of the respondents do not perceive the practice from a religious angle and they thought that religious teaching does not encourage FGM in the study area. During the FGD discussion, one of the religious leaders addressed significant role of religion in that positively influences the lives of individuals' as well as groups of people. For majority of religious individuals it promotes sense of meaning and purpose, always offer hope, and it provide comfort in their lives. It protecting us from any malevolence developments and discourages from any act that not commanded in words of God. Thus, unlike male circumcision, the female circumcision was not commanded in Holy Bible but commonly including religious individuals in our local area all sector of societies performs his/her daughter FGM practice during evening period secretly. Therefore, the participation of religious leaders in the control of FGM is important in large because it liable to mobilize the entire religious members as well as the whole community.

Also according to one of 32 years old FGD religious leader explanations, "in Holy Bible there is no religious requirement regarding the practice of FGM. In the Bible, there is no any command that allow women and girls to have undergone FGM. Often a culture and social pressure encourage people to practice FGM for them but under the circumstance of religion".

According to one of the key informants from office of women, children and youth affairs, 28 years old head office, God knows more what we know about ourselves. God never created badly for females and she is a Christian so she believed in God. In addition, she has accepted his works and commandment of his words because he knows what is good and bad to all human beings regardless of gender. Another 35year-old woman, from one of FGD, stated the cutting of the clitoris was dangerous during the first sexual intercourses and child bearing which resulted high bleeding, and lead to death of women and newborn child respectively. However, communities are not aware with this negative outcome that resulted low community participation in controlling steps forward. The above survey and qualitative data shows that intensive participation of religious institution in the process of controlling FGM in the study can influence the cultural barriers that promote FGM as a sign of purity in the study area. 
The result shows majority (89.6\%) of respondents agreed and strongly agreed with the concept "I perceive that community participation can change the attitude of people towards un-circumcised girl in the locality". Besides the mean $(M=4.42, S D=0.685)$ value revealed that the perceptions of rural community towards the contribution of community participation in changing the attitude of people that they have on the un-circumcised girls is high. It shows the level of community participation in changing the behavior of individuals.

This study found out that different stalk holder's involvement in the process of controlling FGM is crucial. In this regard, the result indicate that majority $(92.4 \%)$ of respondents agree and strongly agree with the statement "active involvement of stakeholders can help to control FGM practice". The perceptions of respondent towards the concept $(M=4.58, S D=0.626)$ based on the value is almost high and positive.

The result of this study indicated that, $88.3 \%$ respondents argued with the statement "participation of community in the control of FGM practice benefits all people in my locality". The mean value ( $M=4.4, S D$ $=0.689$ ) show respondents highly and positively believe the contribution of community participation in the control of FGM practice benefiting all people in the locality. The findings indicated that majority of respondents favored to women and girls become beneficial through community participation in controlling female circumcision.

To sum up, the result of this study on the contribution of community participation in controlling FGM practices in the study area revealed high and positive perception. This implies community engagement in the process of FGM controlling activities has a crucial value.

\section{Community's perception towards their role in bringing behavioral change among local community in controlling FGM}

In this regard, the influence of community participation in making decision to left circumcision of once daughter in the future. The result revealed that $45.0 \%$ and $44.4 \%$ of respondents perceive $(M=4.34, S D=$ 0.661) community participation influence the future actions of an individual can be high and very high respectively. This implies that local community participation can helps them to make decision to leave circumcision of their daughters for the future and tends to be high influence the process of practicing FGM among the community members. Respondents of this study also asked what their intention is to control the FGM practice. The result indicated that $43 \%$ and $43.8 \%$ of the respondents favored, they have high and very high intention to control FGM practices. Nevertheless, the rest $13.4 \%$ of respondents perceived they have medium intension. This result shows that majority of the respondent have the willing in controlling the FGM practices in the study area but the social norm and value system of the community hindering them to culminate the practice.

Moreover, the role of community volunteer's participation in changing the behavior of an individual to control FGM practice assessed. The result of this study revealed that, $35.1 \%$ and $57.9 \%$ of respondents believe community volunteer's participation in changing the behavior of an individual can high and very 
high respectively. The attitude of respondents measured by Likert scale shows $(M=4.56, S D=0.626)$ their perception towards the statement "the role of community volunteers participation in controlling FGM practice" is highly positive.

The role of Kebele polity participation in changing the behavior of individuals in the process of controlling FGM practice was also examined in this study and the result found out that almost all (93.7\%) respondents perceive the role of Kebele polity participation in changing the behavior of individuals in the process of controlling FGM practice is high and very high. The mean value $(M=4.57, S D=0.609)$ also indicates that their perception towards the statement "The role of Kebele polity participation in changing the behavior of an individual in the process of controlling FGM practice" is highly positive.

The degree of community participation in overcoming the social pressure and marginalization of uncircumcised women in the process of controlling FGM was another variable assessed in this study. In this regard, the study found out that $33.2 \%$ and $54.8 \%$ of respondents claim the degree of community participation in overcoming the social pressure and marginalization of uncircumcised women in the process of controlling FGM is high and very high respectively. However, the rest $12 \%$ respondents' perception found at the medium level. The mean value $(M=4.43, S D=0.679)$ calculated from Likert scale attitude measurement towards the statement "The degree of community participation in overcoming the social pressure and marginalization of uncircumcised women in controlling FGM is highly positive.

The qualitative data was gathered from KII and FGD to supplement the survey result. Accordingly, a Female participant (Age $=43$ years old) in FGD elaborated her idea that "The social pressure plays the role either to encourage or discourage FGM because it addressed strictly to what is concern of the groups and communities wanted. Also one of the 33 years old women, FGD participant, talked about communities attempted to synonymous female circumcision with male circumcision in the rural areas. This showed ignorance of the reasons for opposing female circumcision. These Findings revealed that majority of respondents supported that Community Participation enables to overcome social pressure and marginalization to uncircumcised women and girls among local communities.

The degree of participation of community leaders in motivating local community in the process of controlling FGM was assessed. In view of that, the result of this study indicates $31.1 \%$ of the respondents favor the participation of community leaders highly in motivating local community in the process of controlling FGM practices; while $65.4 \%$ respondents perceived highly the participation of community leaders motivate local community in the process of controlling FGM. The mean value $(M=4.62, S D=$ 0.555) also shows respondents perception towards the statement "The degree of participation of community leaders in motivating local community in process of controlling FGM" is positively high.

Based on qualitative data, a 31 years old women, Kebele women and children affairs office, addressed that apart from magnification of community participation the need for establishment of FGM controlling clubs. This can provide technical support and possibly will bring confirmatory behavioral change towards controlling FGM. Also the well-organized and collaborative working relation with local administration, community leaders, religious and 'Edir' leaders must be encouraged to facilitate the controlling 
mechanisms of FGM in the study area. These finding indicated that community leaders' participation highly motivates the partnership among local community in controlling FGM activities.

Participation of local community-based organizations (CBOs) in boosting the process of FGM controlling activity was another variable assessed by the researcher. The study found out that local CBOs participation in changing the behavior of community members is high. Accordingly, the result indicates $36.7 \%$ and $51.6 \%$ from the total respondents perceive participation of local community-based organizations (CBOs) in boosting the process of FGM controlling activity as high and very high respectively. The value $(M=4.64, S D=0.656)$ also complements the frequency distribution data and it indicates the perception of respondents as positively high.

Regarding the intensity of community participation in making legal action to have decisive role in controlling FGM, this study found out that $42 \%$ and $19.0 \%$ of respondents perceive that the intensity of community participation in making legal action to have decisive role in controlling FGM is low and medium. However, the rest $21 \%$ and $18.1 \%$ believing that the intensity of community participation in making legal action to have decisive role in controlling FGM is high and very high. The mean value ( $\mathrm{M}=$ $2.51, S D=0.856)$ shows the perception of the intensity of community participation in making legal action to have decisive role in controlling FGM is approaching to low.

The majority of the FGD participants discussed that they were not aware of any person being punished in the study areas. However, the FGD participant's forwarded community members always attempted to aware if anyone in the community punished by practicing FGM either undergoing female or parents and/or ex-circumcisers. The finding indicates that the intensity of community members in making legal action to have decisive role in the process of controlling FGM is low. Hence, the power of community members mostly inclined to informal sanction than formal legal enforcement.

Accordingly, $37.8 \%$ and $49.2 \%$ from the total respondents perceive that educated spouses actively participating in FGM controlling activity in the study locality in changing the behavior of individuals can be high and very high respectively. The mean value $(M=4.36, S D=0.702)$ also confirms the frequency distribution data and it indicated that educated spouses actively participating in FGM controlling activity to change the behavior of individuals in the community is high.

Lastly, the role of anti-FGM targeted education in bringing progressive participation among local community in controlling FGM in locality as assessed by the researcher is that almost (98.1\%) all of the respondents perceive that the role of anti-FGM targeted education in bringing progressive participation among local community in controlling FGM in locality is high and very high. Accordingly, the mean value ( $M=4.17, S D=0.421)$ also shows that anti-FGM targeted education in bringing progressive participation among local community in controlling FGM in locality is moderately high.

\section{Common challenges during community participation in controlling FGM practice}


The qualitative data supported that accordance to key interview informant woman, 31 years old, FGM practice in rural community has taken a new dimension performed. That means the trend of female circumcision change from public to secrecy between rural communities principally to repulse from penalization.

According to 36 years old FGD participant woman, discussed her view as follows: FGM practice currently organized in secret and mainly at evening. This is partly assuming to hide from government a partner, which does believe not able to know what local community surround happening. During the group discussion, FGD participants acknowledged that the main change in the way to celebrate circumcision performed with increasing preference by using health professionals and a few traditional circumcisers. The practice of FGM is not the decision of undergoing individual woman and girl but it is the decision makers are parents. Key informant interview girl, 28 years old, talked that the community lacked strategic controlling process that emanated with low community involvement during CP in controlling FGM practice among local community. During CP challenges appeared due to low decision making of mothers and fathers towards their daughters in anti-FGM.

One of the FGD participants man, 35-year-old, discussed that:

“... People not considered the existing legal frame and legal criminalized act to make decision in the controlling process. Because he addressed that parents are often liable to facilitate precondition to marriage their daughter so that the circumcision preferable. Likewise, he discussed that FGM practice has high negatively influences on individual females and on her life in the future unless the practice controlled by participation of entire community".

Lack of open discussion among rural community

In comprehensively, in rural area, the local community as whole familiar with continuation of FGM practices. One of FGD participant woman, 32 years old, discussed that the common problem among local people is low commitment by them and absence of open discussion between communities demerits of practice to individual woman and girl in particular and entire community in general.

The key informant interviewed woman, Kebele polity, talked that

“.....the circumcise girls, her parents, practitioners and the communities are living together in one village within community. The issue is still that absence of open discussion between people with one another regarding to control and eliminate the practice once to end. Thus, absence of open discussion among local people becomes one of basic influencing factors to CP in controlling FGM practice”.

As a result, sensitivity of the issue created stumpy participation by local community and permitted the interference of administrative offices in order not to politicize the FGM practice. Both FGD participants and key interview informants, forwarded whatever the involvement of local community and their partaking to enable harmonize and work cooperatively to enhance FGM controlling activity which strained by interference of local government officials. 
Also shifting donors' budget from local to regional and federal stage creating the low involvement of local community based organizations and other local community groups' in an anti-FGM to facilitate controlling activity. Since, to organize participator meeting, conference and workshops on anti-FGM training among local community fund raising and donors support is vital to control FGM practice in the study area.

\section{Discussion}

The campaign to eradicate harmful traditional practices, particularly female genital mutilation, has intensified over the years; the practice is not just a health risk but a human rights violation[14]. The progress of FGM elimination must be faster to achieve sustainable development goal 5.3 and eliminate FGM by 2030. Every women's and girls have the right to protect them from female genital mutilation[20, 21]. So, this study tried to assess the community participation and challenges to control FGM in southwest Ethiopia.

In the current study majority of them were practiced FGM. This is consistence with study conducted in Nigeria[22], Ethiopian demographic health survey 2016, a study conducted in northwestern and western part of Ethiopia [10,23,24]. This might be due to the same sociocultural context of the country and the same level of legal approach from the government perceptive. This implies that implementing culturally acceptable and socially integrated policy and programs is very crucial for the reduction of FGM practices. The qualitative finding also explored that culture is the main gate for to prevent FGM in each community level. So, designing culturally acceptable program needed for the reduction FGM practices.

However, the finding of the current study is lower than the study conducted in Somali region Ethiopia[25], in Amhara region, Ethiopia[26]. This difference might be due to community perception towards the women and women's value difference in each community. A qualitative study also explored that giving high value to the women is very essential to decrease the practice of FGM in the community. But the current study is higher than the study conducted in some part of the study conducted somewhere else in Ethiopia[27]. This might be due to difference in population of the two study and study period.

The current study assess the awareness of women on FGM. In this study, $45.2 \%$ of the study participants were aware on female genital mutilation practice. This is lower than the study conducted in Nigeria[22], Kenya[28] and Saudi Arabia[29].This might be due to difference in intervention from country to country and legal level of the country varies. The country needs to more intervention on female genital mutilation in each aspect and awareness should be create in the community.

This study also revealed that only $17.1 \%$ of the respondents had favor to traditional practice of FGM. This finding is comparable with the study conducted in Somali and Harari Regions, Eastern Ethiopia[30].This might be due to similar sociocultural context of the country and the same legal approach towards FMG. The qualitative study also explored that legal approach of the country is the main issue for the practice of FGM and the wrong deviation of the community. However, this finding is lower than study conducted in 
Amhara region, Ethiopia[23] and the study conducted in Kenya and Nigeria[31].This variation might be due to variation in study population and sociocultural since culture is pillar for the practice of FGM.

The study current study also identify the level of participation to control FGM in community. The qualitative finding explored that community involvement is very crucial for the control of female genital mutilation in each society. One key informant say that FGM is highly attached with the community culture, religion and belief so community engagement is non-optional to reduce the practice of FGM. This is evidenced by the different studies that indicated that community involvement is necessary to end the practice of female genital mutilation[32-34]. This means that FGM is deep rooted with the culture of the community so community by themselves must involve to prevent the practice.

\section{Conclusion And Recommendations}

The practice of FGM in the study are high since the goal of sustainable development goal is zero. Lowe attitude and perception towards female genital mutilation is study area. Majority of FGM practice was done health professionals in secret way. This implies that more intervention is needed for the reduction of its practice. There is different challenges for high practice of FGM in the study area. These challenges changing tradition of female circumcision from public to secrecy, lack of decision making among local people, lack of open discussion among rural community, submissive participation by women in FGM controlling process, intervention of local administration and preference of donors' problem were the main challenges of the community to control female genital mutilation.

The community should discussed on FGM with different stakeholders. The government should work with the community and should consider culturally appropriate and socially acceptable policies and strategy to reduce the practice.

\section{Abbreviations}

\section{CBOs}

Community-based organizations, CP:Community participation, FGD:Focused ground discussion, FGM:Female Genital Mutilation, MCH:Maternal and Child Health, KII:Key informant interview, SPSS:Statistical Package for Social Science, WHO:World Health Organization

\section{Declarations}

\section{Ethics approval and consent to participate}

Ethical clearance was obtained from Institutional Review Board (IRB) of Jimma University, Institute of health, Faculty of public health. Support letter was obtained from woreda and necessary permission was obtained from Woreda health office. Informed verbal consent was obtained from each study participant age above 18. For the study participants whose age less than 18 years informed consent was obtained 
from their family or their husband or guardian. The following procedures were followed to assist study participants who could not read and write: 1) data collector read the content of the informed consent for them; and 2) study participants affirmed their consent to participate in the study by using their thumbprints as a sign of consent. During KII, their informed consent was obtained prior to the interview and voice record. During FGD, each participant aware about the objective and consent was obtained from each individual before discussion started. Anonymity of the participants were kept by not to write their name and individuals information will not be disclosed to other third party and informed verbal consent was obtained from each study participant. Audio and voice record never disclose for the third party. To confirm that all methods were carried out in accordance with relevant guidelines and regulations.

\section{Consent for Publication}

Not applicable

\section{Availability of Data and Materials}

All necessary data included in the manuscript.

\section{Competing interests}

The author declare that have no competing interest.

\section{Funding}

I did not receive any specific fund for this research.

\section{Author contribution}

MS involved from the conception of the study up to preparation of the final draft of the manuscript.

\section{Acknowledgments}

I would like to express my deepest heartfelt thanks to Jimma University for allowing conducting of this study. I would like to thank woreda health office and health extension workers on which the study conduct for their positive responses to facilitate this study. My special thanks also go to study participants, data collectors and supervisors.

\section{References}


1. Costello S, Quinn M, Tatchell A, Jordan L, Neophytou K: In the best interests of the child: Preventing female genital cutting (fgc). British Journal of Social Work 2015, 45(4):1259-1276.

2. Lewnes A: Changing a Harmful Social Convention, Female Genital Mutilation/cutting: United Nations Publications; 2005.

3. Adeyinka A, Adedotun O, Asabi O: Knowledge and practice of female circumcision among women of reproductive ages in South West Nigeria. J Humanit Soc Sci 2012, 2(3):38-45.

4. Nkanatha JK, Karuri MN: Female genital mutilation: Its physical-social effects on individuals and reasons for its persistence among communities. Research on Humanities and Social Sciences 2014, 4(28):93-96.

5. UNHCR: A community-based approach in UNHCR operations. In.: UNHCR Geneva; 2008.

6. Kizilhan JI: Impact of psychological disorders after female genital mutilation among Kurdish girls in Northern Iraq. The European Journal of Psychiatry 2011, 25(2):92-100.

7. Törrönen M, Borodkina O, Samoylova V, Heino E: Empowering Social Work: Research \& Practice. 2013.

8. Helland J, Getachew D: Study of the impact of the work of Save the Children Norway in Ethiopia: building civil society: Norad; 2004.

9. Engelsma B, Mackie G, Merrell B: Unprogrammed abandonment of female genital mutilation/cutting. World Development 2020, 129:104845.

10. CSACE I: Ethiopia demographic and health survey 2016. Addis Ababa, Ethiopia, and Rockville, Maryland, USA: CSA and ICF 2016.

11. Pyati A, De Palma C: Female genital mutilation in the United States: protecting girls and women in the US from FGM and vacation cutting. Sanctuary for Families 2013.

12. Mubita A, Libati $M$, Mulonda $M$ : The importance and limitations of participation in development projects and programmes. European Scientific Journal 2017, 13(5):238-251.

13. Njue C, Karumbi J, Esho T, Varol N, Dawson A: Preventing female genital mutilation in high income countries: a systematic review of the evidence. Reproductive health 2019, 16(1):113.

14. Jones SD, Ehiri J, Anyanwu E: Female genital mutilation in developing countries: an agenda for public health response. European Journal of Obstetrics \& Gynecology and Reproductive Biology 2004, 116(2):144-151.

15. Kiaira AM: The Role of Women Goups in The Methodist Church in Kenya: The Complexity of Fighting Against Poverty. 2014.

16. Yasin Y: Prevalence of female genital mutilation among school girls in El Mansoura Center, ElDakahlia Governorate, Egypt. IOSR Journal of Dental and Medical Sciences 2014, 13:11-76.

17. Setegn T, Lakew Y, Deribe K: Geographic variation and factors associated with female genital mutilation among reproductive age women in Ethiopia: a national population based survey. PloS one 2016, 11(1):e0145329. 
18. Tandawuya NCA: UNFPA-UNICEF joint programme on the abandonment of female genital mutilation in increasing the awareness of community and government toward the harmful practice of fgm in somaliA (2008-2013). President University; 2018.

19. Pankhurst A: Child marriage and female circumcision (FGM/C): evidence from Ethiopia. 2014.

20. Powell R, Mwangi-Powell FN: Female genital mutilation and the Sustainable Development Goals: The importance of research. Health Care for Women International 2017, 38(6):521-526.

21. DU CR: Sustainable development goals. 2016.

22. Johnson OE, Okon RD: Perception and practice of female genital cutting in a rural community in southern Nigeria. African journal of reproductive health 2012, 16(4):132-139.

23. Melese G, Tesfa M, Sharew Y, Mehare T: Knowledge, attitude, practice, and predictors of female genital mutilation in Degadamot district, Amhara regional state, Northwest Ethiopia, 2018. BMC Women's Health 2020, 20(1):1-9.

24. Yirga WS, Kassa NA, Gebremichael MW, Aro AR: Female genital mutilation: prevalence, perceptions and effect on women's health in Kersa district of Ethiopia. International journal of women's health 2012, 4:45.

25. Mitike G, Deressa W: Prevalence and associated factors of female genital mutilation among Somali refugees in eastern Ethiopia: a cross-sectional study. BMC public health 2009, 9(1):264.

26. Moges NA, Mullu G, Gedfew M, Redi M, Molla M, Ayenew S, Fentahun S, Adisie S, Dagnew Z: Knowledge, Attitude and Practice of Women Towards Female Genital Mutilation in Lejet Kebele, Dembecha Woreda, Amhara Regional State, Northwest, Ethiopia, 2014. Journal of Gynecology and Obstetrics 2015, 3(2):21-25.

27. Abebe S, Dessalegn M, Hailu Y, Makonnen M: Prevalence and barriers to ending female genital cutting: the case of Afar and Amhara Regions of Ethiopia. International journal of environmental research and public health 2020, 17(21):7960.

28. Livermore L, Monteiro R, Rymer J: Attitudes and awareness of female genital mutilation: A questionnaire-based study in a Kenyan hospital. Journal of Obstetrics and Gynaecology 2007, 27(8):816-818.

29. Malak M, Basalem D, Aleiidi S, Helabi N, Almutairi M, Alhamed A: Awareness of Female Genital Mutilation/Cutting Among the General Population in 2019: A Survey-based Study in Saudi Arabia. Cureus 2020, 12(1).

30. Abathun AD, Gele AA, Sundby J: Attitude towards the practice of female genital cutting among school boys and girls in Somali and Harari regions, eastern Ethiopia. Obstetrics and gynecology international 2017, 2017.

31. SIDDHANTA A, SINHA A: ATTITUDE AND PERCEPTION TOWARDS FEMALE CIRCUMCISION: A STUDY OF VULNERABILITY AMONG WOMEN IN KENYA AND NIGERIA.

32. Newell-Jones K: Empowering communities to collectively abandon FGM/C in Somaliland. In.: ActionAid; 2016. 
33. Diop NJ, Askew I: The effectiveness of a community-based education program on abandoning female genital mutilation/cutting in Senegal. Studies in family planning 2009, 40(4):307-318.

34. Barrett $H$, Brown $K$, Alhassan $Y$, Beecham D: The REPLACE* Approach: Supporting Communities to end FGM in the EU. Community Handbook. 2015. 